\title{
High-speed compression moulding of CFRTP/AFRTP hybrid composites using an electromagnetic induction heating system
}

\author{
K. Tanaka ${ }^{1}$, M. Yamada ${ }^{2}$, N. Kohashi ${ }^{2} \&$ T. Katayama ${ }^{1}$ \\ ${ }^{I}$ Department of Biomedical Engineering, Doshisha University, Japan \\ ${ }^{2}$ Department of Mechanical Engineering, Doshisha University, Japan
}

\begin{abstract}
Carbon Fibre Reinforced Plastics (CFRP) can offer a great deal of automobile weight saving. For automotive applications, however, they are not used well due to their low energy absorption and long production cycle time. Hybrid composite laminates of Carbon Fibre Reinforced Plastics/Aramid Fibre Reinforced Plastics (CFRP/AFRP), based on thermosetting resin, have a high strength to weight ratio and high energy absorption capacity. When CFRP/AFRP hybrid composite laminates will be used for the mass-produced car, it is necessary to consider the recycling efficiency and productivity. Therefore, it is preferable to use thermoplastics resin.

The high-speed compression moulding method using an electromagnetic induction heating system has a big advantage for the moulding of continuous fibre reinforced thermoplastic composites, because this thermoforming technique could reduce the production cycle time drastically. In this study, a Carbon Fibre/Aramid Fibre Reinforced Thermoplastics hybrid composite (CFRTP/ AFRTP) was manufactured by the high-speed compression moulding method using an electromagnetic induction heating system, and the optimum moulding condition and mechanical properties of CFRTP/AFRTP hybrid composites were investigated.

An optimum moulding condition was sought by using the design of experiments method. The factors used in this study were moulding pressure, maximum temperature holding time, materials and stacking sequences. An optimum moulding condition was determined from the analysis of variance by mechanical properties. The optimum moulding condition of the CFRTP/AFRTP
\end{abstract}


hybrid composite that has CFRTP outermost layers has a moulding pressure of $4 \mathrm{MPa}$ and holding time of 90 seconds.

Keywords: thermoplastic composites, hybrid composites, aramid fibre, carbon fibre, electromagnetic induction, high speed compression moulding.

\section{Introduction}

In the automobile industry, from the point of preventing global warming, mass reduction of automotive bodies has become more important than ever. In particular, automotive weight lightening by using Carbon Fibre Reinforced Plastics (CFRP), which has the advantages of high-specific strength and highspecific modulus, has been receiving a lot of attention [1]. Although the demand for CFRP is increasing in the aerospace industry, its application to the automobile industry is limited, due to the low impact resistance and high forming cost of CFRP $[2,3]$.

To improve the impact resistance of CFRP, hybrid composites of Aramid Fibre Reinforced Plastics (AFRP) with Carbon Fibre Reinforced Plastics based on thermosetting resin have been studied $[4,5]$. However, there are problems in that recycling efficiency and productivity are low in the case of thermosetting resin. When CFRP/AFRP hybrid composites are used for the mass-produced car, it is preferable to use thermoplastics resin due to the mentioned problems.

For the moulding method of the continuous fibre reinforced thermoplastics, hot press compression is usually used. In mass production situations, due to the extended time needed for pre-heating and cooling of moulds and materials, preheating equipment and multiple toolings are necessary. To reduce the cost, the development of an applicable moulding method for mass production is expected. In our previous study, a high-speed compression moulding method by means of an electromagnetic induction heating system for Carbon Fibre Reinforced Thermoplastics (CFRTP) using Non-woven Stitched Multiaxial Cloth (NSMC) has been successfully developed [6]. The electromagnetic induction heating system has a big advantage for moulding of continuous fibre reinforced thermoplastic composites, as this thermoforming technique can reduce production cycle time drastically.

In the hybrid composites, there are a great number of design parameters that strongly affect the bending and impact behaviour of composite materials. It has been reported that the stacking sequence of different fabrics plays an important role in determining the bending and impact property of hybrid composites [7]. Furthermore, the mechanical properties of FRP are strongly affected by moulding conditions, such as moulding pressure and holding times.

In this study, Carbon Fibre/Aramid Fibre Reinforced Thermoplastics hybrid composites (CFRTP/AFRTP) were produced by the high-speed compression moulding method using an electromagnetic induction heating system. The optimum moulding condition and mechanical properties of CFRTP/AFRTP hybrid composites were investigated. 


\section{Materials and experimental procedure}

\subsection{Moulding method}

Test specimens were moulded by the high-speed compression moulding method using an electromagnetic induction heating system [6]. Fig.1 shows the schematic drawing of the electromagnetic induction heating system. When an electrical current runs through an inductor, a magnetic field is generated. The magnetic field penetrates the mould placed inside the inductor, and creates an induced current on the mould surface. Since the current concentrates within the mould surface by the skin effect, the mould surface generates heat by the Joule effect. The principal advantage of the electromagnetic induction heating system is that the heat source locates close to the material. There is no longer any need to preheat the mould or the materials before placing it in the mould. Fig.2 shows an example of the temperature history of the mould surface during the moulding process. It takes only about 70 seconds to heat up from $50{ }^{\circ} \mathrm{C}$ to $250{ }^{\circ} \mathrm{C}$; the cooling process from $250^{\circ} \mathrm{C}$ to $50^{\circ} \mathrm{C}$ requires only about 150 seconds.

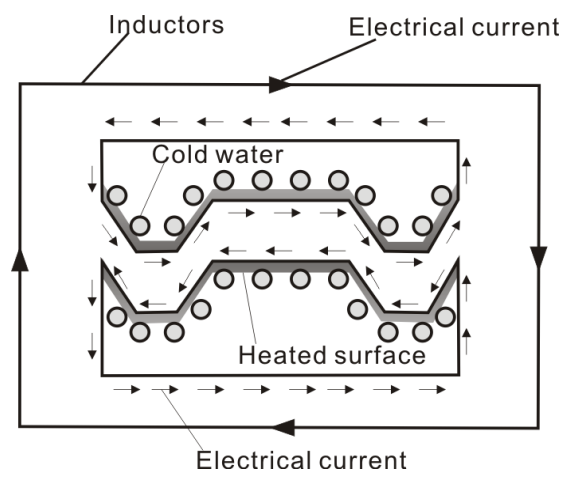

Figure 1: Schematic drawing of the electromagnetic induction heating system.

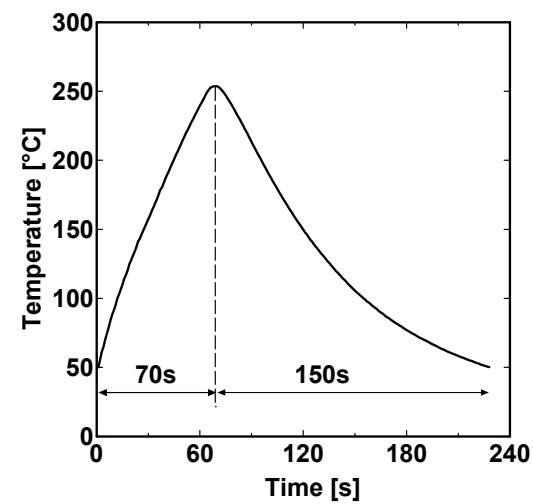

Figure 2: Temperature history of the mould surface during the moulding process. 


\subsection{Materials}

Polyamide 6 (Ube Industries, Ltd., Japan) was used for a matrix. It is processed into non-woven fabric by the melt blown method (Kuraray Co., Ltd., Japan) with weight per unit area at $50 \mathrm{~g} / \mathrm{m}^{2}$. For CFRTP, a multi-axial multi-ply carbon fabric/non-woven fabric (Non-woven Stitched Multiaxial Cloth; NSMC, 400 $\mathrm{g} / \mathrm{m}^{2},\left[0^{\circ} / 90^{\circ}\right]$, Benny-Toyama Co. Ltd., Japan) was used for the semi product. NSMC consists of the non-crimp stitched carbon fabric and the non-woven PA6 fabric, being stitched together by polyester sewing thread.

For AFRTP, two types of aramid fabric, plain fabric of twaron ${ }^{\circledR}$ and plain fabric of technora ${ }^{\circledR}$ (Teijin Techno Products Limited) were used. The weight per unit area of these aramid fabrics was $440 \mathrm{~g} / \mathrm{m}^{2}$.

\subsection{Experimental parameter}

The moulding condition, materials and stacking sequence were narrowed down by using experimental design and optimum moulding condition was determined. Four factors were selected for evaluation, including moulding pressure $(1,3,5$ $[\mathrm{MPa}])$, holding times at maximum temperature $(0,30,60[\mathrm{~s}])$, materials (carbon fibre, aramid plain fabric (twaron ${ }^{\circledR}$ ), aramid plain fabric (technora $\left.{ }^{\circledR}\right)$ ) and stacking sequence $(\mathrm{A}: \mathrm{X} / \mathrm{CF} / \mathrm{CF} / \mathrm{CF} / \mathrm{CF} / \mathrm{X}, \mathrm{B}: \mathrm{CF} / \mathrm{CF} / \mathrm{X} / \mathrm{X} / \mathrm{CF} / \mathrm{CF}, \mathrm{C}: \mathrm{CF} / \mathrm{X} / \mathrm{CF} /$ $\mathrm{CF} / \mathrm{X} / \mathrm{CF}, \mathrm{X}$ is the material selected from three types). All factors were set to three levels. Table 1 shows the $\mathrm{L}^{9}\left(3^{4}\right)$-type orthogonal array, representing the combination of the factors and the levels of the experiments. In this study, moulding temperature was set to $250^{\circ} \mathrm{C}$ based on our previous study [6].

\subsection{Mechanical testing}

Three points bending tests were conducted, following the recommended testing procedures as described in JIS-K7017. The test specimens were cut out from the moulded composites using a water jet. The length and width of the specimens

Table 1: $\quad \mathrm{L}^{9}\left(3^{4}\right)$-type orthogonal array.

\begin{tabular}{|c|c|c|c|c|}
\hline & $\begin{array}{c}\text { Moulding } \\
\text { pressure } \\
(\mathrm{MPa})\end{array}$ & $\begin{array}{c}\text { Holding time at } \\
\text { maximum } \\
\text { temperature (s) }\end{array}$ & Material & $\begin{array}{c}\text { Stacking } \\
\text { sequence }\end{array}$ \\
\hline 1 & 1 & 0 & carbon & $\mathrm{A}$ \\
\hline 2 & 1 & 30 & twaron & $\mathrm{B}$ \\
\hline 3 & 1 & 60 & technora & $\mathrm{C}$ \\
\hline 4 & 3 & 0 & twaron & $\mathrm{C}$ \\
\hline 5 & 3 & 30 & technora & $\mathrm{A}$ \\
\hline 6 & 3 & 60 & carbon & $\mathrm{B}$ \\
\hline 7 & 5 & 0 & technora & $\mathrm{B}$ \\
\hline 8 & 5 & 30 & carbon & $\mathrm{C}$ \\
\hline 9 & 5 & 60 & twaron & $\mathrm{A}$ \\
\hline
\end{tabular}


were $80 \mathrm{~mm}$ and $15 \mathrm{~mm}$, respectively. The specimen support span was set for 60 $\mathrm{mm}$. The bending test was conducted by the universal material testing machine INSTRON 5566. The cross-head displacement rate was $1 \mathrm{~mm} / \mathrm{min}$.

Charpy impact tests were conducted, following the recommended testing procedures as described in JIS-K7061. The test specimens were cut out from the moulded composites using a water jet. The length and width of the specimens were $80 \mathrm{~mm}$ and $10 \mathrm{~mm}$, respectively. The momentum of the hammer's pendulum was $4.9 \mathrm{~N} \cdot \mathrm{m}$.

Puncture impact tests were conducted, following the recommended testing procedures as described in JIS-K7211-2. The test specimens were cut out from the moulded composites using a water jet. The length and width of the specimens were both $60 \mathrm{~mm}$. A high-speed impact test was conducted by HTM-10KN (Shimadzu Corporation) at an impact velocity of $4.5 \mathrm{~m} / \mathrm{s}$.

The void content was calculated using the following equation. $\rho_{\text {th }}$ is the theoretical density and $\rho_{\text {meas }}$ is the specimen density.

$$
X_{v}=\frac{\rho_{\text {th }}-\rho_{\text {meas }}}{\rho_{\text {th }}}=1-\frac{\rho_{\text {meas }}}{\rho_{\text {th }}}
$$

\section{Results and discussion}

\subsection{Optimization of the moulding conditions}

\subsubsection{Examination of factors and levels}

Analysis of variance at $1 \%$ significance level was performed on the bending strength, Charpy impact strength and puncture energy. The moulding pressure, holding times, materials and stacking sequence were significant factors affecting the bending strength. The holding times and stacking sequence were significant factors affecting the Charpy impact strength. Furthermore, the stacking sequence was a significant factor affecting the puncture energy. Fig.3(a) shows the influence of the moulding pressure on bending strength. The bending strength at $3 \mathrm{MPa}$ was higher than that at $1 \mathrm{MPa}$. The bending strength at $3 \mathrm{MPa}$ was almost the same as that at $5 \mathrm{MPa}$. Hence, the optimum moulding pressure seems to be around $3 \mathrm{MPa}$. Fig.3(b) shows the influence of the holding time on the bending strength and Charpy impact strength. The bending strength showed an increasing tendency when holding time increased. The Charpy impact strength reached a peak at a holding time of 30 seconds. In this study, with respect to the bending strength, 60 seconds is selected for the optimum holding times. Fig.3(c) shows the influence of the materials on the bending strength and Charpy impact strength. The bending strength of CFRTP/AFRTP hybrid composites was lower and the Charpy impact strength was higher when compared to CFRTP composites. The bending strength and Charpy impact strength of technora was higher than that of aramid fabric twaron. Consequently, technora was chosen as the material within this study. Fig.3(d) shows the influence of the stacking sequence on bending strength and puncture energy. Stacking sequence A had the highest puncture energy in all conditions. Stacking sequence $\mathrm{C}$ had the highest 


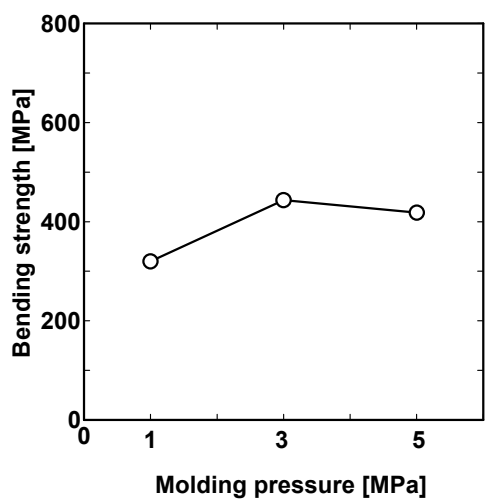

(a) Relationship between moulding pressure and bending strength.

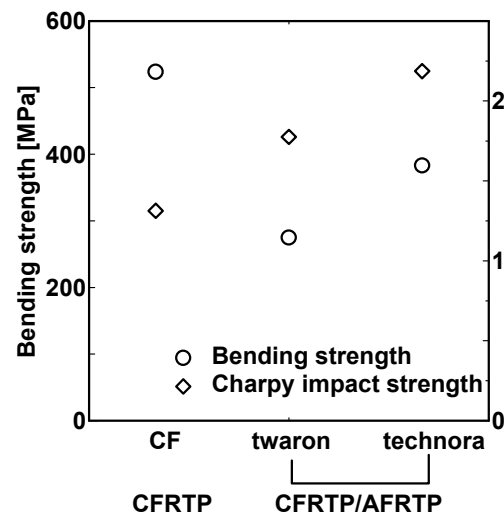

Reinforced fiber

(c) Relationship between reinforced fibre and bending strength and Charpy impact strength.

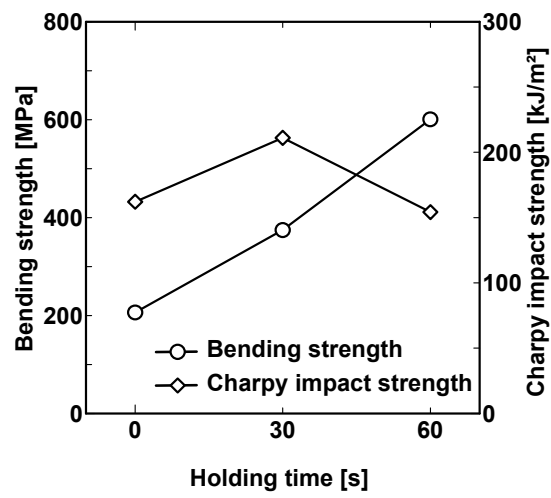

(b) Relationship between moulding time and bending strength and Charpy impact strength.

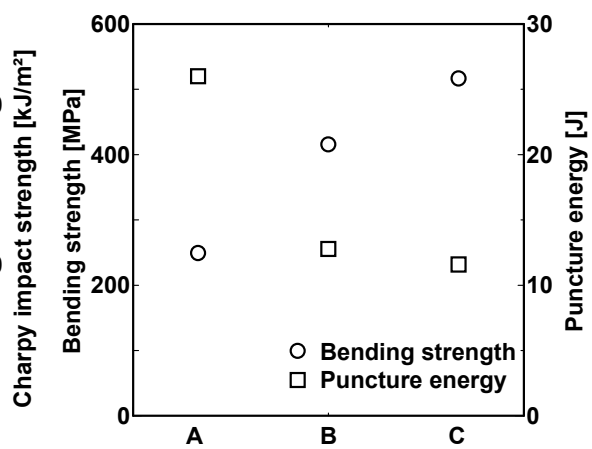

Stacking sequence

(d) Relationship between stacking sequence and bending strength and puncture energy.

Figure 3: $\quad$ Mechanical properties of CFRTP/AFRTP hybrid composites.

bending strength in all condition. Stacking sequence C, with an excellent bending strength, was chosen as the stacking sequence within this study.

\subsubsection{Selection of moulding conditions}

From the result of fig.3, technora and stacking sequence $\mathrm{C}$ have been chosen as the material and stacking sequence. In order to determine the optimum moulding conditions, moulding at various pressures (3, $4 \mathrm{MPa})$ and at holding times (60, 90, 120 s) were carried out. Fig.4(a) shows the bending strength in each moulding condition. A small difference was shown in the bending strengths of $3 \mathrm{MPa}$ and $4 \mathrm{MPa}$, and this result corresponded with the analysis of variance 
trend shown in fig.3. The bending strength was virtually constant regardless of holding times at $4 \mathrm{MPa}$. The bending strength showed an increasing tendency when holding times increased at $3 \mathrm{MPa}$. The bending strength for $3 \mathrm{MPa}$ at 120 seconds was the same as that of all holding times at $4 \mathrm{MPa}$. Fig.4(b) shows the void content in each moulding condition. As the holding times increased, resin impregnation seemed to be better and bending strength improved. At $3 \mathrm{MPa}$, when holding times increased the void content decreased. While at $4 \mathrm{MPa}$, the void content rate remained constant to all holding times. When comparing $3 \mathrm{MPa}$ and $4 \mathrm{MPa}$, the void content for $3 \mathrm{MPa}$ at 120 seconds was the same as that of all holding times at $4 \mathrm{MPa}$. Fig.5 shows the Charpy impact strength in each moulding condition. There was a small difference in the average Charpy impact strength. The dispersion of Charpy impact strength for 90 seconds holding time

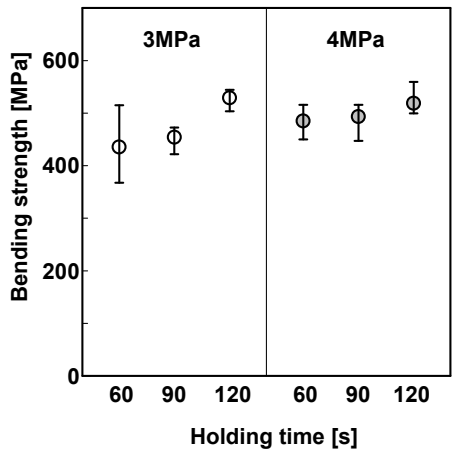

(a) Bending strength of CFRTP/ AFRTP (stacking sequence C).

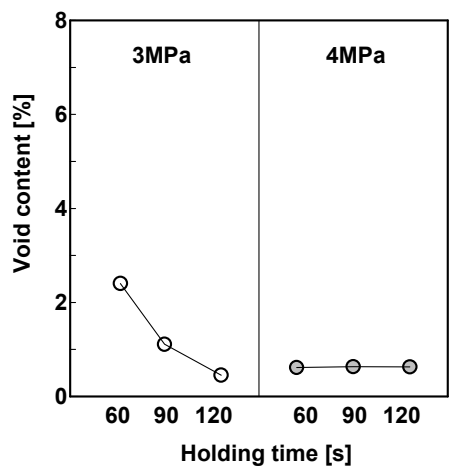

(b) Void content of CFRTP/AFRTP (stacking sequence $\mathrm{C}$ ).

Figure 4: Bending strength and void content of CFRTP/AFRTP hybrid composites.

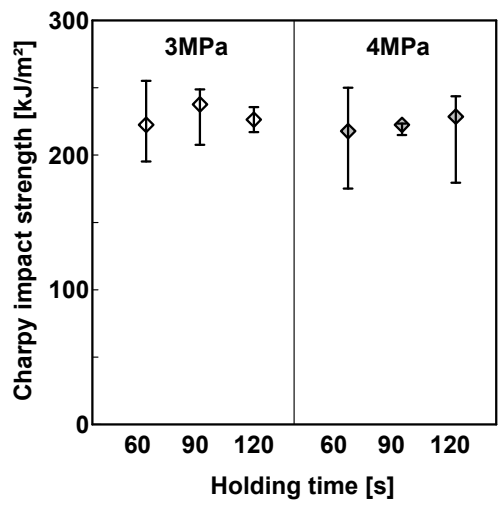

Figure 5: Charpy impact strength of CFRTP/AFRTP (stacking sequence C). 
at $4 \mathrm{MPa}$ was small. Therefore, the moulding pressure of $4 \mathrm{MPa}$ and the holding times of 90 seconds were determined as being the optimum moulding conditions in view of the moulding cycle.

\subsection{Mechanical property of a hybrid composite moulded by the optimum moulding condition}

It can be considered that the CFRTP/AFRTP hybrid composites are flexible in achieving any bending strength or Charpy impact strength by changing the proportion of CFRTP to AFRTP. The moulding condition of the specimens is listed in Table 2. CAC63 shows the stacking sequence of $[\mathrm{CF} / \mathrm{CF} / \mathrm{AF} / \mathrm{AF} / \mathrm{CF} / \mathrm{CF}]$ and $63 \%$ carbon fibre ratio to all fibres. Thereupon the influence of the bending property and Charpy impact property to the proportional combination of CFRTP and AFRTP are examined.

\subsubsection{Bending properties}

Fig. 6 shows the relationship between the carbon fibre ratio and bending strength in stacking sequence $\mathrm{C}$. The bending strength of CAC63 was $542 \mathrm{MPa}$,

Table 2: $\quad$ Moulding condition of the specimens.

\begin{tabular}{|c|c|c|c|c|}
\hline \multicolumn{2}{|c|}{ Specimen } & Stacking sequence & $\begin{array}{l}\text { Moulding } \\
\text { pressure }\end{array}$ & $\begin{array}{c}\text { Holding time } \\
\text { at } \\
\text { maximum } \\
\text { temperature }\end{array}$ \\
\hline \multicolumn{2}{|c|}{ CFRTP } & {$\left[0^{\circ} / 90^{\circ}\right]_{3 \mathrm{~s}}$} & \multirow{4}{*}{$4 \mathrm{MPa}$} & \multirow{4}{*}{$250^{\circ} \mathrm{C}$} \\
\hline \multirow{2}{*}{$\begin{array}{l}\text { CFRTP/ } \\
\text { AFRTP }\end{array}$} & CAC63 & [CF/CF/AF/AF/CF/CF] & & \\
\hline & CAC77 & [CF/CF/AF/CF/CF] & & \\
\hline \multicolumn{2}{|c|}{ AFRTP } & [Plain fabric $]_{9}$ & & \\
\hline
\end{tabular}

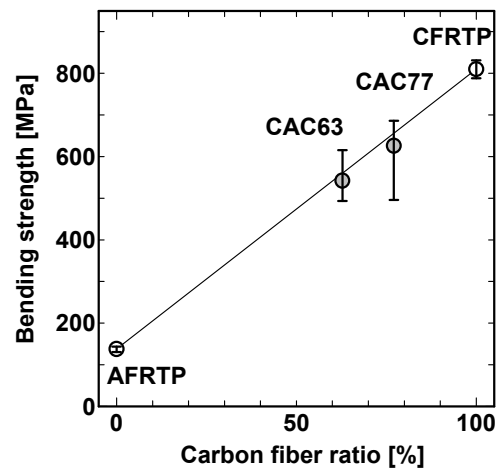

Figure 6: Relationship between the carbon fibre ratio and bending strength. 
approximately $67 \%$ of the bending strength of CFRTP. The bending strength of CAC77 was $626 \mathrm{MPa}$, approximately $78 \%$ of the bending strength of CFRTP. The bending strength was increased in proportion to the carbon fibre ratio. Fig.7 shows the stress-strain diagram of CFRTP, CFRTP/AFRTP and AFRTP. For CFRTP, an initial fracture was observed at the compression side of CFRTP when strain was at around $1.2 \%$, followed by fracture occurring at the tension side. The stress of CAC63 and CAC77 increased linearly up to around $0.8 \%$ strain as strain increased. After that, the elastic modulus decreased gradually, and the stress decreased rapidly at around $1.6 \%$ strain. AFRTP showed the yielding behaviour at around $1.5 \%$ strain.

\subsubsection{Charpy impact properties}

Fig. 8 shows the relationship between the carbon fibre ratio and Charpy impact strength in stacking sequence C. The Charpy impact strength of CAC63 was 212 $\mathrm{kJ} / \mathrm{m}^{2}$, approximately $134 \%$ of the Charpy impact strength of CFRTP. The Charpy impact strength of CAC77 was $175 \mathrm{~kJ} / \mathrm{m}^{2}$, approximately $110 \%$ of the

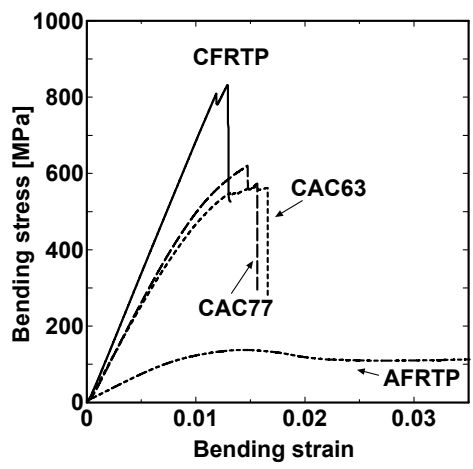

Figure 7: $\quad$ Stress-strain curves for CFRTP, CFRTP/AFRTP and AFRTP.

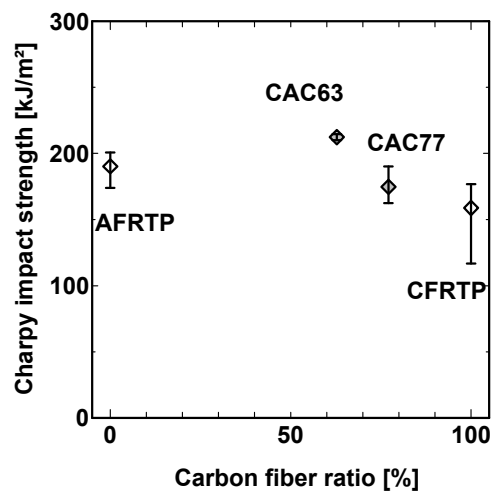

Figure 8: Relationship between the carbon fibre ratio and Charpy impact strength. 
Charpy impact strength of CFRTP. The Charpy impact strength of CAC77 was comparable to that of AFRTP, while the Charpy impact strength of CAC63 exceeded that of AFRTP. The CFRTP/AFRTP hybrid composites, although slightly weaker in bending strength than CFRTP, are comparable in Charpy impact strength to that of AFRTP.

\section{Conclusion}

In this study, CFRTP/AFRTP hybrid composites were produced by the high-speed compression moulding method. The optimum moulding condition and mechanical properties of CFRTP/AFRTP hybrid composites were investigated. The investigation yielded the following conclusions.

1. CFRTP/AFRTP hybrid composites are successfully developed using the highspeed compression moulding method by means of an electromagnetic induction heating system.

2. For CFRTP/AFRTP hybrid composites moulded by high-speed compression moulding, the optimum moulding conditions are moulding pressure at $4 \mathrm{MPa}$ and holding times at 90 seconds.

3. CFRTP/AFRTP hybrid composites, although slightly weaker in bending strength than CFRTP, are comparable in Charpy impact strength to that of AFRTP.

\section{Acknowledgement}

This study was partially supported by the High technological research project on "Research and Development Center for Advanced Composite Materials" of Doshisha University and Ministry of Education, Culture, Sports, Science and Technology, Japan.

\section{References}

[1] Takahashi, J., Datusekiyugijyututoshitenojidousyakeiryoukanohoukousei, Seikei-Kakou, Japan, 20(6), pp. 318-323, 2008.

[2] Kawatsu, Y. \& Noguchi, K., Perforation Impact Behaviour of CFRP Laminates, J. Soc. Mater. Sci., Japan, 41(464), pp. 721-727, 1992.

[3] Carney, D., Automotive Engineering International, pp. 55-58, 2005.

[4] Nakata, M., Miyano, Y., Suzuki, M. \& Hattori, Y., A Study on Material for Flexural Behaviour of Carbon/Aramid Hybrid FRP Laminates. J. Soc. Mater. Sci., Japan, 41(462), pp. 349-355, 1992.

[5] Gustin, J., Joneson, A., Mahinfalah, M. \& Stone, J., Low velocity impact of combination Kevlar/carbon fibre sandwich composites. Composite Structure, 69, pp. 396-406, 2005.

[6] Tanaka, K., Kohashi, N., Kinoshita, Y., Katayama, T. \& Uno, K., Compression Molding of Carbon Fiber Reinforced Thermoplastics Using 
Non-Woven Stitched Multi-Axial Cloth by Means of Induction Heating System. J. Soc. Mater. Sci., Japan, 58(7), pp. 642-648 2009.

[7] Onal, L. \& Adanur, S., Effect of Stacking Sequence on the Mechanical Properties of Glass-Carbon Hybrid Composites Before and After Impact. Journal of Industrial Textiles, 31(4), pp. 255-271, 2002. 